\title{
NOTAS MARXINAIS Á POESÍA DE ALVARO CUNQUEIRO
}

\section{Teresa López}

Universidade da Coruña

doi:10.17075/mucnoc.2014.023 

Forcadela, M. / T. López / D. Vilavedra (coords.) (2014): Mil e un cunqueiros. Novas olladas para un centenario, Santiago de Compostela, Consello da Cultura Galega. doi:10.17075/mucnoc.2014. pp. 465-478

Estas páxinas recollen notas, ideas, datos, suxestións sobre a poesía de Álvaro Cunqueiro. Son achegas do punto de vista dunha lectora e admiradora dos poemas de Cunqueiro, que deseñan un vieiro persoal, non sistemático, que pon o foco nalgúns aspectos da poesía de Cunqueiro, que considero interesantes, ou coido que foron menos atendidos.

Falar da poesía de Cunqueiro supón, de inicio, termos que esclarecer a que poesía nos estamos a referir. Como para boa parte dos grandes autores galegos contemporáneos, carecemos aínda de edicións de referencia da súa obra literaria (non falamos necesariamente dunha obra completa) ou, mesmo, dunha bibliografía exhaustiva. Esta carencia é moi relevante no caso do Cunqueiro poeta por varias razóns: a súa dilatada obra, a súa ampla traxectoria como escritor, a publicación dunha parte importante dos seus textos en xornais, revistas, folletos ou plaquetas (algúns, os menos, aínda esquecidos; outros que, no mellor dos casos, permaneceron alleos ás eventuais reedicións que si gozaron as obras publicadas en libro). Isto polo que di respecto da difusión e do acceso á obra poética de Álvaro Cunqueiro para calquera lector, fóra de círculos académicos máis ou menos restrinxidos.

Á carencia dun corpus poético de Cunqueiro definitivo e delimitado, a pesar dos avances dos últimos anos ${ }^{1}$, súmase a ausencia de textos fixados logo dun proceso de edición crítica realizado con rigor filolóxico, tanto máis necesario canto que unha boa parte dos poemas de Cunqueiro se publicaron en datas diferentes e con variantes textuais máis ou menos relevantes. Os exemplos son moitos, mais podemos tomar como referencia un dos poemas máis celebrados de Cunqueiro: «Pero Meogo no verde prado». Antes de editarse con este título en Herba aqui e acolá (Cunqueiro 1980), saíu publicado, cando menos dúas veces, e con títulos diferentes, a primeira, como «Donde muere el corzo» (en Faro de Vigo en 1953, segundo apuntara César Antonio Molina), unha segunda, como «Homaxe a Pero

1 A última achega, a edición de Costas e Castro Buerguer (Cunqueiro 2011), que acrecenta novos poemas e pon a cuestión das falsas traducións. Con anterioridade, deben destacarse, entre outras contribucións concretas, as achegas de Costas (Costas 1991a, Costas1991b, Cunqueiro 1991a). 
Meogo» (en Vida Gallega, en 1961, segundo sinalou Xesús Alonso Montero). Ademais, Cunqueiro citouno nos seus artigos, nalgún caso reproducindo versos, e cunha distribución diferente á versión logo fixada na Obra completa, como no artigo «Ciervos y corzos poéticos», de 1975 (Cunqueiro 1994: 193).

Aínda máis, a utilización de pseudónimos para dar a coñecer finxidas traducións de poetas inexistentes — chamada "falsa alofonía» ou "alofonía fantástica», en palabras dos seus editores últimos, Xosé Henrique Costas e Iago Castro Buerguer (Cunqueiro 2011) — descubriunos un número aínda por determinar de poemas apócrifos que viñeron a complicar aínda máis a delimitación dos contornos da obra poética do autor mindoniense. Uns contornos difusos canto ao volume da obra poética, ás súas características e até na definición do criterio autoral.

Referirémonos, pois, á poesía de Álvaro Cunqueiro, sendo conscientes de que, ao falarmos dela, estamos aínda a traballar con outra dificultade engadida: a unicidade da obra de creación do autor mindoniense, a miúdo subliñada pola crítica. Cunqueiro foi, como poucos escritores galegos, un creador total, que fai realidade o principio dos vasos comunicantes entre os xéneros. A presenza recorrente de elementos de hibridación xenérica en cada unha das súas obras, as obras teatrais e narrativas nas que se incrustan con frecuencia pezas doutros xéneros, os artigos xornalísticos que insiren poemas... E, o máis relevante para o asunto que nos ocupa, os poemas que xorden, unha e outra vez, en paralelo á obra narrativa e teatral.

O propio Cunqueiro deixou explicado este proceso de creación:

Todos esos poemas de ambiente árabe: Os catro xefes da casa de Gingiz e Os setenta pavillós, nacieron cuando escribía Cuando el viejo Sinbad regrese a las islas. Es decir, al mismo tiempo que trabajo en prosa me van surgiendo poemas paralelamente. Lo mismo me sucedió cuando estaba escribiendo Un hombre que se parecía a Orestes o Las Mocedades de Ulises. Son creaciones paralelas, que tienen ese ambiente, esa patética de la narración. Muchas veces esos poemas también se incorporaron a mis novelas (Molina 1981).

É certo que son palabras que parecen aplicarse singularmente aos poemas de Herba aqui e acolá agrupados so o rótulo común «As historias»e, nese sentido, limitaríanse á fase final da súa obra literaria. Fala o Cunqueiro ancián, na que vén considerándose a súa última entrevista, a que realizou César Antonio Molina para o xornal Pueblo, publicada postumamente. 
Mais para un lector non especialista, o Cunqueiro poeta estivo e continúa a estar nos poemarios publicados en forma de libro (Mar ao Norde, Cantiga nova que se chama ribeira, Poemas do si e do non, Dona do corpo delgado e Herba aquí e acolá) que compuxeron o primeiro volume da Obra completa. Poesía. Teatro que saíu do prelo da editorial Galaxia en 1980. Fóra desta compilación de referencia, quedaron moitos poemas. Nalgún caso, integraban poemarios que finalmente viron a luz, como Somas de craridades (1977), mais, ás máis das veces, quedarían sen publicarse nos volumes para os que foran imaxinados: Favorábel prisón de sono, Poemas antigos, A luz i-outros poemas, Adolescenza no inverno, Caravaneiros da alba, Cantos de Hastings... Na súa maior parte, foron incorporados aos poemarios publicados e, sobre todo, pasaron a engrosar esa abondosa produción poética dispersa, encaixada en textos xornalísticos ou difundida en publicacións periódicas.

A aparición de Herba aqui e acolá, no seo do primeiro volume dunha Obra completa que nunca acabou de completarse de todo, redescubriu Álvaro Cunqueiro como poeta e contribuíu a subliñar o lugar central da poesía na súa obra: o escritor nacía e despedíase como poeta, ante todo poeta. Desfacíase así, en certa forma, a imaxe dun escritor que fora poeta nos anos mozos e que destacara logo, principalmente, no xénero narrativo. Poeta en galego, narrador logo en galego e en castelán, cunha carreira literaria como narrador en español premiada, mais nunca realmente acabada de rematar polo éxito.

En certa forma, aínda hoxe Cunqueiro é, mesmo para o público culto, un narrador ou un contador de historias (en boa medida pola imaxe como personaxe público que el mesmo construíu), máis que calquera outra figura que un escritor poida ter. Un narrador en galego, mais tamén en español. Mentres, a poesía sempre se identificou coa obra en galego, fóra dun libro como Elegías y canciones (1940), tan marcado pola data da súa publicación, e en certa forma agochado pola traxectoria posterior do autor, pola súa mesma singularidade, polo feito de ser, en boa parte, un compendio de poemas xa publicados en galego.

Se ben é certo que Cunqueiro fixo a súa presentación pública como escritor cun poemario de vangarda, e en galego, tamén é certo que antes de Mar ao norde (1932) ensaiou outras orientacións poéticas. Entre elas, queremos chamar a atención para un grupo de poemas publicados maioritariamente en 1930, de pendor claramente saudosista: son "Algún día ...?», «Lonxanías esmorrentes», 
«Ben quixera» (os tres publicados en 1930) e "No máis esvío cume» (publicado en 1933). O editor dos tres últimos, Xosé Henrique Costas, sinalara xa «a súa fasquía asonetada, a época común na que foron escritos, e a pegada — nós cremos que evidente- de Noriega e Aquilino» (Costas 1991a: 6). No seu momento, xa sinalaramos como Cunqueiro bebía, coma outros poetas do seu tempo (o propio Iglesia Alvariño), do portugués Teixeira de Pascoaes, figura de referencia para o nacionalismo cultural galego na década dos trinta (López 1995).

Neses primeiros anos de escribir e publicar poesía, Cunqueiro nin foi de inicio poeta de vangarda nin se limitou, só, a ser un poeta de vangarda. Tampouco foi só poeta en galego. Un exemplo, o poema que traemos aquí, publicado en 1931 en Céltiga, a revista de referencia para a comunidade galega en Bos Aires, que contara coa colaboración dos mellores escritores e artistas gráficos galegos. Titúlase «Romanza y canción del buen recordar. Soneto»; está dedicado a Elida, en Bos Aires, e datado en Mondoñedo. Reproducímolo:

Azul, azul, color de tus ojos: claro,

la canción y el romancillo del buen recordar!

Azul, azul, invierno, y campos en flor de amaro,

y el placer de recordarte en la otra orilla del mar!

Caminos lejos del Sol; ¡Oh la dulce amiga mía!

Velero, velero rubio, caballito de humo en alas:

Déjame a la alegría, grande alegría,

de verla, adornada con sus galas!

¡Azul, azul!.. ¡Cielo y mar!... Mis amigos:

cerrad del Templo postigos...

vamos a pasar el mar...

Todos juntos, de las manos; muy sencillo

nuestro íntimo pensar; yo os diré el romancillo

canción del Buen Recordar!...

Neste poema están presentes trazos que remiten á poesía máis recente de Cunqueiro: a fórmula sonetística, a lembranza como motivo; á posterior, no seu ciclo inicial vangardista: un certo inxenuísmo lúdico (como en Cantiga nova que se chama riveira), o mar (como en Mar ao norde); e algún outro que se pode conside- 
rar común a ambos os dous, como unha certa caracterización da figura feminina. É tamén un poema cancioneiril (a pesar da roupaxe de soneto), claramente no ronsel de Marinero en tierra e La amante, de Rafael Alberti, moito máis que calquera outro dos poemas de Cunqueiro que a crítica quixo colocar, unha e outra vez, á sombra neopopularista do poeta gaditano. A utilización do castelán como lingua poética probablemente non sexa allea a esta escolla xenérica, e quizais teña tamén que ver coa identidade e a localización en Arxentina da destinataria feminina do poema.

«Romanza y canción del buen recordar» pode resultar unha anécdota no conxunto da obra do escritor mindoniense e non pretendemos elevar a anécdota a categoría, mais contribúe para iluminar a etapa inicial do Cunqueiro poeta e matizar a asociación de inicio e de raíz do poeta coa vangarda máis extrema, xa apuntada noutros poemas, ou dunha vocación literaria vinculada á lingua galega, e só modificada logo pola Guerra Civil.

De feito, a poesía de Cunqueiro padeceu a simplificación etiquetadora á que moitas veces somos propensos desde o ámbito académico: vangardismo, popularismo, culturalismo foron os termos que pretenderon identificar (e reducir) a súa poesía. E, sobre todo, a etiqueta que máis incomodaba a Cunqueiro: a do neotrobadorismo. Tanto que, nunha entrevista do ano 1977 que lle fixo Xavier Navaza, se queixou amargamente desa recorrencia á hora de cualificalo como poeta:

Iso é unha parvada!... Unha parvada! Esa puñetera manía do noso País de non entender nada e, sobre todo, de non face-lo menor esforzo por entender (Navaza 1977).

A identificación co neotrobadorismo quizais haxa que explicala non só pola énfase que desde certos sectores do galeguismo cultural se puxo neste aspecto da obra de Cunqueiro (pensemos na «Carta a Álvaro Cunqueiro, trovador galego, falándolle dos males presentes de Europa e do seu remedio, dende a ladeira dun castro lugués» de Ramón Piñeiro, de 1951), senón tamén porque acaía perfectamente ao pasadismo con que a obra narrativa de Cunqueiro se identificaba, de forma que ambas as dúas etiquetas acabaron por reforzarse mutuamente.

Tamén contribuíu a esta simplificación o feito de que o último poemario publicado polo mindoniense fose precisamente Cantiga nova que se chama Riveira, o emblema do Cunqueiro neotrobador, nunha reedición do ano 1957, que 
acrecentaba novos poemas, o cal non fixo máis que reforzar a identificación do autor, do poeta, coa revisión do trobadorismo de que estamos a falar.

Isto explica, en boa medida, que a publicación do primeiro volume da Obra en galego completa, cando Cunqueiro era xa un escritor célebre, no cabo da súa vida, e, singularmente, de Herba aqui e acolá, puidese supor a descuberta dun poeta. Outra cuestión diferente é que a admiración que o poemario levantou se traducise nunha influencia directa nos poetas dos oitenta.

Fóra da conflitiva relación de Álvaro Cunqueiro coa súa condición de neotrobador, o certo é que Cunqueiro foi un lector intenso e continuo das cantigas. $\mathrm{O}$ mozo de vinte e catro anos que era no ano 1936 respondía ao «Inquérito previo a unha Escolma da lírica galega» que lle dirixira Filgueira Valverde, no apartado «Poesía galega»:

Non teño criterio formado. Coido que non hai mais que Canzoneiros, Rosalía, Pondal, Carballo e Manuel Antonio. Entre todos eles percebo certo amor e parentesco, coma o sinto entre Iglesia Alvarińo i-eu, sen que seipa en que pende (Cunqueiro 1991b).

A pesar do que parece unha dúbida inicial, a resposta é ben contundente: Cunqueiro redefine a tradición literaria (poética) galega para a pór á par dos clásicos, dos seus clásicos, a vangarda. Unha e outra vez volverá sobre estes autores, para glosalos, homenaxealos, dalos a coñecer e cońecelos mellor el propio. A diferenza, no caso dos cancioneiros, vai estar no interese desde diferentes instancias do galeguismo cultural en promover a existencia do neotrobadorismo como característico da poesía galega, en facer de Cunqueiro o seu referente e no suceso que unha certa forma de facer poesía neotrobadoresca vai acadar nos anos cincuenta.

Para termos unha idea cabal e completa da poesía de Álvaro Cunqueiro, cómpre non esquecer que, para alén de poeta, Cunqueiro foi editor (xa desde a mocidade, nos Papeis de color), tradutor (con singular e constante dedicación, sobre todo nas súas colaboracións xornalísticas), crítico (máis ocasional e non por iso menos vehemente) e un gran divulgador de poesía, da poesía galega e da poesía toda, de calquera tempo e lugar, aproveitando calquera intervención oral ou escrita, en medios especializados ou de difusión xeral. No caso da poesía galega, merece destaque especial o seu afán por difundir a lírica trobadoresca, cantigas e trobadores; o seu labor crítico, con recensións tanto de obras literarias como de ensaios críticos, nalgunha ocasión con resultados sorprendentes (pensamos de 
novo nunha recensión de poesía medieval, a que, como Álvaro Labrada, publica en 1969 no Faro de Vigo sobre As once cantigas de Johan Zorro, en edición de Manuel Alvar, dunha virulencia pouco habitual), e tamén a súa condición de divulgador de poetas e poemas, mesmo dos que, en aparencia, podían parecer máis distantes dos seus postulados estéticos.

Neste sentido, queremos salientar unha súa colaboración na revista Destino, a que so o título "Joven poesía gallega» se publica no número 1324 da cabeceira barcelonesa, de decembro de 1963 . O rótulo encabeza unha escolma de poetas e poemas da xeración dos 50: Xosé Luís Franco Grande, Bernardino Graña, Ramón Lorenzo, Alexandre Cribeiro, Avilés de Taramancos, Salvador García Bodaño, Xosé Luís Méndez Ferrín e Arcadio López Casanova son os autores dos oito poemas seleccionados.

Son, los que firman estos poemas, los poetas más jóvenes de la lengua gallega, de tan antigua e ilustre tradición lírica. Cantan a su modo, que no es, naturalmente, el de los claros trovadores o el de Rosalía, el de Noriega o el de Manuel Antonio. En el antigo vaso de la lengua hay un nuevo licor, acaso muchas veces excesivamente amargo. Poetas muy distintos entre sí, quizá los unan, además del acento de esta década del siglo, unánimes preocupaciones por el ser y el existir, una angustiada nostalgia, una estremecida rebusca en la humana desesperanza, poetas solidarios, al fin, con la gallega gente cotidiana en el oscuro terrón y en la ola atlántica, donde combate humilde y misérrimamente al sol y a la lluvia de los días. Galicia escucha en ellos su voz eterna, constantemente visitada por irreprochables primaveras (Cunqueiro 1963).

Cunqueiro funciona como mestre de cerimonias, presentando os novos poetas galegos ante un público lector maioritariamente non galego. Actúa na súa condición de escritor galego de referencia e recońece así o relevo xeracional que supuxeran estes poetas, os da chamada xeración das Festas Minervais. Pon a súa tribuna en Destino e o seu prestixio cultural ao servizo da difusión da literatura máis nova de Galiza. Este feito é interesante por varios motivos. É máis un elemento que contribúe a desfacer a idea dunha suposta distancia (se non ignorancia mutua ou rexeitamento) entre Cunqueiro e os escritores galegos mozos e, neste sentido, unha mostra de como funcionaban os mecanismos de cohesión marcada polo uso da lingua e pola pertenza a unha mesma literatura, por riba de grupos xeracionais, ideolóxicos ou estéticos. Mais, ante todo, é un moi notable exercicio 
de aproximación e apropiación duns poetas e duns poemas ben lonxe da súa poética, de empatía poética. Vai procurar nestes poemas a identificación coa mesma xente de aquí e de acolá que el retratará, le a mesma nostalxia que impregnará a súa poesía de madurez e a mesma desesperanza que tentará conxurar unha e outra vez a través da palabra poética. O mesmo acento da década que oe nos novos poetas tampouco era un son tan alleo a Álvaro Cunqueiro.

En «Volando con el trueno», auténtica declaración autopoética integrada no volume Laberinto y cía, vai expor claramente como a súa obra de creación é, tamén, unha forma de literatura humanista, de reaccionar fronte ás incertezas que sacoden o home contemporáneo:

Digo todo esto para que se vea que soy el ser menos imaginativo que ande por ahí, y que lo más propio mío es sumar noticias que muestren lo vario que es el mundo, y lo ricamente, y con cuántas sorpresas, se puede almacenar la memoria humana. Yo, que no desconozco los grandes temas del siglo, y estoy atento a eso que llaman la coyuntura histórica, y acepto la gran patética de mi tiempo y quiero ayudar, en lo que me sea posible y aún bastante más, al hombre de estos días, tantas veces puesto en el filo de la navaja, no me dejo asustar por los profesionales de la angustia, y busco en la gran peripecia humana, tantas veces mágica aventura, tantas veces sueños espléndidos y mitos trágicos, la razón de continuar.

De continuar contra la miseria, contra la violencia, contra el terror, contra la mentira. Es el hombre el animal más extraño, que decía el Estagirita, pero también la hierba más debil. Resiste porque sueńa, y porque el amor hace olvidar el hambre. Yo no me evado ni ayudo a nadie a evadirse: me enfrento, simplemente, con los tristes, porque creo que la tristeza traiciona la condición humana. Dante encontró a los tristes en el Infierno. Le decían al gibelino: «Tristes fuimos en el dulce aire que del sol se alegra...» El gibelino y yo vamos, al borde de la tiniebla, creyendo que toda hora es alba (Cunqueiro 1970: 77).

Nesta longa citación, como no artigo enteiro, Cunqueiro explíca(se)nos enteiro: actitude vital, función da arte, ars poetica, filiación literaria, relación entre literatura e realidade, compromiso e evasión... Poucas veces encontraremos unha expresión tan acabada, exacta e sincera dun poeta, dun escritor, que alcance o sentido todo da súa obra e que acabe por converterse nunha confesión da razón poética.

Cunqueiro resístese á etiqueta de escritor de «evasión e imaxinación», no sentido de que isto supońa desentenderse do tempo histórico e, sobre todo, da com- 
prensión da condición humana; esclarece frases feitas e desfai malentendidos. Presenta a súa obra literaria arraigada na realidade, nunha realidade plural («sumar noticias que muestren lo vario que es el mundo») que pende, en última instancia, de como a lembramos e (re)construímos, do home e da capacidade deformadora, creadora, da memoria.

$\mathrm{Na}$ capacidade de superar os aspectos máis adversos da realidade, encontra Cunqueiro a auténtica condición humana: a capacidade de sońar e a capacidade de amar, como bases de resistencia e de supervivencia. Estas, a través da palabra do poeta, volven facer o mundo.

Poemas como "Acolá están as illas...», incluído en "Novas sombras e vellos cantos» de Herba aqui e acolá, expresan en fermosas imaxes o afán de ver máis alá, que Cunqueiro cre inherente á condición humana:

A alma anda nestes inventos porque non lle abonda

o que é como é do mundo

quixer facer pombas con auga e amieiros de pruma

e en vez do carro que polos camińos do monte

baixase cantando a lúa arrastrada

por un tiro de peixes prateados.

As imaxes de estirpe amadocarballiana mostran a aspiración a que a imaxinación poética poida transmutar e superar a realidade. Mais rapidamente o poeta bota as contas e parece renderse, na prosaica aritmética, á imposibilidade de vencer a soidade, a tristura, o medo:

Pro estes inventos soio sirven

pra distraer a alma das suas contas,

tanto de amor e bágoas, dez por cento

de perdidos amores, e oitenta de soedade

que a vistes áspera como unha camisa de estopa

e queres pór unha ollada de seda no mencer

e nóna tés, vecińo da tristura e do medo

a metade de ti morto sin enterrar

pra que a outra metade se decate. 
Ao final, é a palabra creadora, unha e outra vez articulada en canto na poesía de Cunqueiro, que vén a confirmar, de novo, que é onde o ser humano pode encontrar só a razón de continuar:

Entón disimulando canto, e coas mentiras

fágome unha sorrisa de xardín en festas (Cunqueiro 1980: 167).

Unha e outra vez, os poemas do Cunqueiro de plena madurez van acreditar na capacidade da palabra poética para crear a realidade:

Pro nós, amor, temos os cans fideis das verbas.

Decimos cinza i é pó agora mesmo o que foi chama.

Ofelia, dís, e unha sorrisa alerta a túa memoria

e os ollos teus, rula, nena e soave terciopelo (Cunqueiro 1980: 173).

Efectivamente, «O poeta escolle abril». Vaino escoller teimudamente, unha e outra vez.

Vai ser nos poemas compilados en Herba aqui e acolá onde máis cumpridamente se mostren as obsesións de Cunqueiro: a meditación sobre o amor e a morte, o paso do tempo, a identidade, a nostalxia, a procura do paraíso... Mais a mudanza de ton vital, o camińo da reflexividade, a apertura de novos mundos poéticos están xa en Dona de corpo delgado, un volume que ficou sepultado baixo a etiqueta do neotrobadorismo, por mor da sección "Cantigas do amor cortés». Está nas soedades e nas elexías, mais tamén nas cantigas, especialmente nos rondeaux e, sobre todo, no poema final, «Agora trobo o vento e máila lúa fría».

Agora trobo o vento e máila lúa fría, non o cervo do monte que a ágoa volvía.

Agora trobo o mare e máila nao veleira, non a amiga que canta só da abelaneira.

Agora trobo a lúa e máilo vento airado, non o cervo do monte, meu amigo pasado.

Agora trobo a nao e máila mar maior, e non aquela amiga, mińa branca señor (Cunqueiro 1980 [1950]: 132). 
O poeta continúa a cantar, mais inevitablemente afastado agora daquel universo gozoso no que se acubillara: xa non hai cervos no monte nin amiga so a abeleira. Queda só a nave veleira e o mar maior.

Unha e outra vez, o poeta maior que Álvaro Cunqueiro foi resístese a testemuñar a derrota do paraíso. Mais non pode evitar escribir poemas en que, en palabras doutro enorme poeta, «A concentración de dor, autenticidade, confesión, palabra inaudita, presencia da decadencia, pode chegar a ser de leitura inaturábel» (Méndez Ferrín 1984: 166), como acontece en «Ese alguén de meu que nunca volve» (Cunqueiro 1980: 181), no que, a pesar de todo, se impón a memoria como a capacidade humana que permite, de novo, máis unha vez, a supervivencia:

Pro eu resucitarei que soio volven

os que recordan, compañeiros. 


\section{REFERENCIAS BIBLIOGRÁFICAS}

Costas, Xosé Henrique (1991a): «Unha trintena de poemas esquecidos de Álvaro Cunqueiro», Animal 1, 6-9.

Costas, Xosé Henrique (1991b): «Unha trintena de poemas esquecidos de Álvaro Cunqueiro (II e...)», Animal 2, 8-11.

Cunqueiro, Álvaro (1963): «Joven poesía gallega», Destino 1324.

Cunqueiro, Álvaro (1970): Laberinto y cía, Táber, Barcelona.

Cunqueiro, Álvaro (1980): Obra en galego completa. I. Poesía. Teatro, Galaxia, Vigo.

Cunqueiro, Álvaro (1991a): Herba aquí ou acolá, ed. de Xosé Henrique Costas, Galaxia, Vigo.

Cunqueiro, Álvaro (1991b): Autopoética e poesias. 1935, Consello da Cultura Galega, Santiago de Compostela.

Cunqueiro, Álvaro (1994): Papeles que fueron vidas, ed. de Xesús González Gómez, Tusquets, Barcelona.

Cunqueiro, Álvaro (2011): Dona do corpo delgado. Herba aquí e acolá. Outros poemas. Poesía 1933-1981, ed. de Xosé Henrique Costas e Iago Castro Buerger, Galaxia, Vigo.

López, Teresa (1995): «Algún día...? Poema de Álvaro Cunqueiro», Boletín Galego de Literatura 14, 113-117. Méndez Ferrín, Xosé Luís (1984): De Pondal a Novoneyra, Xerais, Vigo.

Molina, César Antonio (1981): «Álvaro Cunqueiro. Lo mío es contar por contar», Pueblo 7.3.1981.

Navaza, Xavier (1977): «Álvaro Cunqueiro. As puñeteras manías do noso país», Teima 30. 